\title{
METODE PERSAMAAN RICCATI PROYEKTIF DAN APLIKASINYA PADA PENYELESAIAN PERSAMAAN LOTKA-VOLTERA DISKRIT
}

\author{
DEASY WAHYUNI, MAHDHIVAN SYAFWAN \\ Program Studi Magister Matematika, \\ Fakultas Matematika dan Ilmu Pengetahuan Alam, Universitas Andalas, \\ Kampus UNAND Limau Manis Padang, Indonesia, \\ email : deasywahyuni1@gmail.com
}

\begin{abstract}
Abstrak. Dalam paper ini akan dijelaskan kembali penurunan metode Riccati Proyektif dalam menyelesaikan persamaan diferensial-beda. Secara khusus metode ini diterapkan pada penyelesaian persamaan Lotka-Voltera diskrit. Dengan bantuan Maple, diperoleh sejumlah solusi eksak dari persamaan tersebut termasuk solusi soliton dalam bentuk fungsi sinh dan cosh.
\end{abstract}

Kata Kunci: Metode persamaan Riccati proyektif, persamaan Lotka-Voltera diskrit, persamaan diferensial-beda

\section{Pendahuluan}

Gelombang nonlinier sering muncul pada fenomena alam, seperti dinamika fluida, kinematika reaksi kimia, matematika biologi dan fisika optik. Dalam banyak kasus, fenomena alam tersebut dimodelkan secara matematis dalam sebuah persamaan diferensial. Meningkatnya kajian terhadap model-model persamaan diferensial dan persamaan diferensial-beda dalam menjelaskan fenomena gelombang nonlinier (kontinu dan diskrit), membuat semakin berkembangnya metode-metode alternatif dalam menyelesaikan persamaan-persamaan tersebut secara eksak. Beberapa diantara metode yang sering digunakan adalah metode tanh, metode invers scattering, metode dekomposisi adomain dan metode persamaan Riccati proyektif $[3,6,8]$.

Pada paper ini akan dikaji kembali secara lebih detail penurunan dan penerapan metode persamaan Riccati proyektif dalam menyelesaikan persamaan diferensialbeda nonlinier. Metode ini digagas pertama kali oleh Conte dan Musette pada tahun 1992 dalam menentukan solusi soliton pada persamaan diferensial parsial nonlinier yang dapat dinyatakan sebagai polinomial dari dua fungsi elementer yang memenuhi suatu sistem Riccati proyektif [1]. Solusi soliton sendiri adalah gelombang nonlinier terlokalisasi (gelombang soliter) yang memiliki sifat dapat mempertahankan bentuknya saat merambat pada kecepatan konstan, meskipun setelah berinteraksi dengan gelombang soliter lainnya [2].

Pada tahun 2003, Yan mengembangkan lebih lanjut metode Contes dan Musette ini dengan memperkenalkan persamaan Riccati proyektif yang lebih umum [7]. Selanjutnya Zhen dan Hong-Qing pada tahun 2006 menerapkan metode persamaan 
Riccati proyektif ini pada dua persamaan diferensial-beda nonlinier, yaitu persamaan Lotka-Voltera dan Korteweg-de Vries (KdV) diskrit [8]. Pada artikel ini akan dieksplorasi kembali referensi [8] dengan melakukan beberapa perbaikan pada penulisan persamaan dan menampilkan visualisasi solusi yang diperoleh.

\section{Penurunan Metode Persamaan Riccati Proyektif}

\subsection{Konstruksi Awal}

Pandang bentuk umum dari persamaan diferensial-beda berikut:

$H\left(u_{n+n_{1}}(t), \cdots, u_{n+n_{k}}(t), u_{n+n_{1}}^{\prime}(t), \cdots, u_{n+n_{k}}^{\prime}(t), \cdots, u_{n+n_{1}}^{(r)}(t), \cdots, u_{n+n_{k}}^{(r)}(t)\right)=0$,

dengan $n, n_{j} \in \mathbb{Z}$, dimana $u_{i}$ menyatakan variabel tak-bebas ke- $i, t$ menyatakan variabel bebas, dan $u_{i}^{(r)}(t)$ menyatakan turunan ke- $r$ dari $u_{i}$ terhadap $t$.

Selanjutnya perkenalkan transformasi gelombang berjalan

$$
u_{n}(t)=U\left(\xi_{n}\right),
$$

dengan

$$
\xi_{n}=d n+c t+\xi_{0}
$$

dimana $d>0$ menyatakan bilangan gelombang, $c \neq 0$ menyatakan kecepatan gelombang, dan $\xi_{0} \in \mathbb{R}$ menyatakan beda fasa. Dengan demikian persamaan (2.1) menjadi $H\left(U\left(\xi_{n+n_{1}}\right), \cdots, U\left(\xi_{n+n_{k}}\right), U^{\prime}\left(\xi_{n+n_{1}}\right), \cdots, U^{\prime}\left(\xi_{n+n_{k}}\right), \cdots, U^{(r)}\left(\xi_{n+n_{1}}\right), \cdots, U^{(r)}\left(\xi_{n+n_{k}}\right)\right)=0$.

Kita ingin menentukan solusi dari persamaan (2.4) yang berbentuk

$$
U\left(\xi_{n}=A_{0}+\sum_{i=1}^{N}\left(A_{i} f\left(\xi_{n}\right)+B_{i} g\left(\xi_{n}\right)\right) f^{i-1}\left(\xi_{n}\right),\right.
$$

dimana $A_{0}, A_{i}$ dan $B_{i}$ adalah konstanta-konstanta yang akan ditentukan nilainya.

Dengan menggunakan prinsip dominant balance (dalam hal ini antara orde tertinggi dari suku nonlinier dan orde tertinggi dari suku turunan), nilai $N$ dapat ditentukan.

Untuk sebarang bilangan bulat $n, f\left(\xi_{n}\right)$ dan $g\left(\xi_{n}\right)$ memenuhi persamaan Riccati proyektif

$$
\begin{aligned}
& f^{\prime}\left(\xi_{n}\right)=p f\left(\xi_{n}\right) g\left(\xi_{n}\right), \\
& g^{\prime}\left(\xi_{n}\right)=q+p g^{2}\left(\xi_{n}\right)-r f\left(\xi_{n}\right) .
\end{aligned}
$$

dengan $p, q, r \in \mathbb{R}$ dan $p \neq 0$.

Selanjutnya $f\left(\xi_{n+k}\right)$ dan $g\left(\xi_{n+k}\right)$ dapat ditulis sebagai fungsi terhadap $f\left(\xi_{n}\right)$ dan $g\left(\xi_{n}\right)$, yaitu

$$
\begin{aligned}
& f\left(\xi_{n+k}\right)=\Psi\left(f\left(\xi_{n}\right), g\left(\xi_{n}\right)\right), \\
& g\left(\xi_{n+k}\right)=\Phi\left(f\left(\xi_{n}\right), g\left(\xi_{n}\right)\right) .
\end{aligned}
$$

Dengan menggunakan persamaan (2.6), (2.7), (2.8) dan (2.9), substitusikan persamaan (2.5) ke persamaan (2.4) dan tetapkan nol untuk semua koefisien dari 
$f\left(\xi_{n}\right)^{i} g\left(\xi_{n}\right)^{j}$ dengan $j=0,1$ dan $i=0,1, \cdots$, sehingga diperoleh sistem persamaan aljabar nonlinier terhadap $A_{0}, A_{i}, B_{i}, c$ dan $d$. Dengan menyelesaikan sistem persamaan tersebut, maka solusi dari persamaan diferensial-beda dapat ditentukan dalam bentuk (2.5).

\subsection{Analisis Metode Persamaan Riccati Proyektif}

Dari persamaan (2.6) diperoleh

$$
g\left(\xi_{n}\right)=\frac{f^{\prime}\left(\xi_{n}\right)}{p f\left(\xi_{n}\right)},
$$

dengan $p \neq 0$ dan $f^{\prime}\left(\xi_{n}\right) \neq 0$. Substitusi persamaan (2.10) ke persamaan (2.7) menghasilkan

$$
f^{\prime \prime}\left(\xi_{n}\right) f\left(\xi_{n}\right)-2\left[f\left(\xi_{n}\right)\right]^{\prime 2}-p q\left[f\left(\xi_{n}\right)\right]^{2}+p r\left[f\left(\xi_{n}\right)\right]^{3}=0 .
$$

Untuk mendapatkan solusi persamaan (2.11), diperkenalkan transformasi berikut:

$$
f\left(\xi_{n}\right)=\frac{1}{w\left(\xi_{n}\right)}, \quad w\left(\xi_{n}\right) \neq 0 .
$$

Dengan menggunakan aturan rantai, turunan pertama dari $f\left(\xi_{n}\right)$ diberikan oleh

$$
\frac{f^{\prime}\left(\xi_{n}\right)}{f\left(\xi_{n}\right)}=-\frac{w^{\prime}}{w} .
$$

Substitusi persamaan (2.13) ke persamaan (2.10) menghasilkan

$$
g=-\frac{w^{\prime}}{p w} .
$$

Lebih lanjut, turunan kedua dari $f\left(\xi_{n}\right)$ diberikan oleh

$$
f^{\prime \prime}=\frac{2\left(w^{\prime}\right)^{2}}{w^{3}}-\frac{w^{\prime \prime}}{w^{2}} \text {. }
$$

Substitusikan persamaan $(2.12),(2.13)$ dan (2.15) ke persamaan (2.11), sehingga diperoleh

$$
w^{\prime \prime}+p q w-p r=0 .
$$

Untuk menentukan solusi persamaan (2.16), pandang tiga kasus berikut: Kasus (i): $p q<0$.

Solusi persamaan (2.16) pada kasus ini diberikan oleh

$$
w=\frac{1}{q}\left(r+q s \cosh \left(\sqrt{-p q} \xi_{n}\right)+q h \sinh \left(\sqrt{-p q} \xi_{n}\right)\right) .
$$

Jika $p=-1$ dan $q=1$, maka dengan mensubstitusikan persamaan (2.17) ke persamaan (2.12), diperoleh

$$
f\left(\xi_{n}\right)=\frac{1}{r+s \cosh \left(\xi_{n}\right)+h \sinh \left(\xi_{n}\right)} .
$$


14 Deasy Wahyuni, Mahdhivan Syafwan

Selanjutnya dengan mensubstitusikan persamaan (2.17) ke persamaan (2.14), didapatkan

$$
g\left(\xi_{n}\right)=\frac{s \sinh \left(\xi_{n}\right)+h \cosh \left(\xi_{n}\right)}{r+s \cosh \left(\xi_{n}\right)+h \sinh \left(\xi_{n}\right)} .
$$

Dengan mengkuadratkan persamaan (2.19) dan melakukan manipulasi aljabar diperoleh

$$
g^{2}\left(\xi_{n}\right)=1-2 r f\left(\xi_{n}\right)+\left(r^{2}+h^{2}-s^{2}\right) f^{2}\left(\xi_{n}\right) .
$$

Dari (2.18) dan (2.19) diperoleh

$$
\begin{aligned}
\cosh \left(\xi_{n}\right) & =\frac{-f\left(\xi_{n}\right) r s-g\left(\xi_{n}\right) h+s}{f\left(\xi_{n}\right)\left(-h^{2}+s^{2}\right)} \\
\sinh \left(\xi_{n}\right) & =\frac{f\left(\xi_{n}\right) h r+g\left(\xi_{n}\right) s-h}{f\left(\xi_{n}\right)\left(-h^{2}+s^{2}\right)}
\end{aligned}
$$

Karena

$$
\begin{aligned}
& \sinh (a+b)=\sinh (a) \cosh (b)+\cosh (a) \sinh (b), \\
& \cosh (a+b)=\cosh (a) \cosh (b)+\sinh (a) \sinh (b),
\end{aligned}
$$

maka

$$
\begin{aligned}
f\left(\xi_{n+k}\right) & =f\left(\xi_{n}+\xi_{n+k}-\xi_{n}\right) \equiv f\left(\xi_{n}+\omega_{k}\right) \\
& =\frac{1}{\left.r+s \cosh \left(\xi_{n}+\omega_{k}\right)+h \sinh \left(\xi_{n}+\omega_{k}\right)\right)} \\
& =\frac{-f\left(\xi_{n}\right)}{-\sinh \left(\omega_{k}\right) g\left(\xi_{n}\right)-r f\left(\xi_{n}\right)+\cosh \left(\omega_{k}\right) f\left(\xi_{n}\right) r-\cosh \left(\omega_{k}\right)}
\end{aligned}
$$

Dengan cara yang sama untuk $g\left(\xi_{n+k}\right)$ diperoleh

$$
\begin{aligned}
g\left(\xi_{n+k}\right) & =g\left(\xi_{n}+\xi_{n+k}-\xi_{n}\right) \equiv g\left(\xi_{n}+\omega_{k}\right) \\
& =\frac{s \cosh \left(\xi_{n}+\omega_{k}\right)+h \sinh \left(\xi_{n}+\omega_{k}\right)}{r+s \cosh \left(\xi_{n} \omega_{)}+h \sinh \left(\xi_{n} \omega_{k}\right)\right.} \\
& =\frac{-\sinh \left(w_{k}\right)-\cosh \left(\omega_{k}\right) g\left(\xi_{n}\right)+\sinh \left(\omega_{k}\right) f\left(\xi_{n}\right) r}{-f\left(\xi_{n}\right) r-\sinh \left(\omega_{k}\right) g\left(\xi_{n}\right)+r f\left(\xi_{n}\right) \cosh \left(\omega_{k}\right)-\cosh \left(\omega_{k}\right)} .
\end{aligned}
$$

Kasus (ii): $p q>0$

Solusi dari persamaan (2.16) untuk kasus ini adalah

$$
w=\frac{1}{q}\left(r+s \cos \left(\sqrt{p q} \xi_{n}\right)+h \sin \left(\sqrt{p q} \xi_{n}\right)\right) .
$$

Misalkan $p=1$ dan $q=1$, maka diperoleh

$$
f\left(\xi_{n}\right)=\frac{1}{r+s \cos \left(\xi_{n}\right)+h \sin \left(\xi_{n}\right)} .
$$

Selanjutnya persamaan (2.14) menjadi

$$
g\left(\xi_{n}\right)=\frac{s \sin \left(\xi_{n}\right)-h \cos \left(\xi_{n}\right)}{r+s \cos \left(\xi_{n}\right)+h \sin \left(\xi_{n}\right)} .
$$


Dengan mengkuadratkan persamaan (2.29) dan melakukan manipulasi aljabar diperoleh

$$
g^{2}=-1+2 r f\left(\xi_{n}\right)-\left(r^{2}-h^{2}-s^{2}\right) f^{2}\left(\xi_{n}\right) .
$$

Selesaikan persamaan (2.28) dan (2.29), sehingga diperoleh

$$
\begin{aligned}
& \cos \left(\xi_{n}\right)=-\frac{f\left(\xi_{n}\right) r s+g\left(\xi_{n}\right) h-s}{\left(s^{2}+h^{2}\right) f\left(\xi_{n}\right)}, \\
& \sin \left(\xi_{n}\right)=-\frac{-h-g\left(\xi_{n}\right) s+h f\left(\xi_{n}\right) r}{\left(s^{2}+h^{2}\right) f\left(\xi_{n}\right)} .
\end{aligned}
$$

Dengan melakukan cara yang sama pada kasus (i), diperoleh

$$
\begin{gathered}
f\left(\xi_{n+k}\right)=-\frac{f\left(\xi_{n}\right)}{-r f\left(\xi_{n}\right)-\cos \left(\omega_{k}\right)+\cos \left(\omega_{k}\right) f\left(\xi_{n}\right) r+\sin \left(\omega_{k}\right) g\left(\xi_{n}\right)}, \\
g\left(\xi_{n+1}\right)=\frac{-\cos \left(\omega_{k}\right) g\left(\xi_{n}\right)+\sin \left(\omega_{k}\right) f\left(\xi_{n}\right) r-\sin \left(\omega_{k}\right)}{-r f\left(\xi_{n}\right)-\cos \left(\omega_{k}\right)+\cos \left(\omega_{k}\right) f\left(\xi_{n}\right) r+\sin \left(\omega_{k}\right) g\left(\xi_{n}\right)} .
\end{gathered}
$$

Kasus (iii): $q=0$.

Solusi dari persamaan (2.16) untuk kasus ini adalah

$$
w=\frac{1}{2}\left(p r \xi_{n}^{2}+C_{1} \xi_{n}-C_{2}\right) .
$$

Substitusikan persamaan (2.34) ke persamaan (2.12) dan (2.14), sehingga diperoleh berturut-turut

$$
\begin{aligned}
& f\left(\xi_{n}\right)=\frac{2}{\left.p r \xi_{n}^{2}+C_{1} \xi_{n}-C_{2}\right)}, \\
& g\left(\xi_{n}\right)=-\frac{2 p r \xi_{n}+C_{1}}{\left(p r \xi_{n}^{2}+C_{1} \xi_{n}-C_{2}\right) p} .
\end{aligned}
$$

Dengan mengkuadratkan persamaan (2.36) dan melakukan manipulasi aljabar diperoleh

$$
g^{2}\left(\xi_{n}\right)=\frac{2 r f\left(\xi_{n}\right)}{p}+\frac{\left(C_{1}^{2}+4 C_{2} p r\right) f^{2}\left(\xi_{n}\right)}{4 p^{2}} .
$$

Penyelesaian persamaan (2.35) dan persamaan (2.36) untuk $C_{1}$ dan $C_{2}$ diberikan oleh

$$
\begin{aligned}
C_{1} & =-\frac{2 p\left(f\left(\xi_{n}\right) r+g\left(\xi_{n}\right)\right)}{f\left(\xi_{n}\right)}, \\
C_{2} & =-\frac{f^{3}\left(\xi_{n}\right) p r+2 g^{2}\left(\xi_{n}\right) p+2}{f\left(\xi_{n}\right)} .
\end{aligned}
$$

Dengan cara yang sama pada kasus (i), kita peroleh

$$
\begin{aligned}
f\left(\xi_{n+k}\right) & =\frac{2 f\left(\xi_{n}\right)}{\operatorname{pr} \omega_{k}^{2} f\left(\xi_{n}\right)-2 p g\left(\xi_{n}\right) \omega_{k}+2}, \\
g\left(\xi_{n+k}\right) & =\frac{2 g\left(\xi_{n}\right)-2 f\left(\xi_{n}\right) r \omega_{k}}{\operatorname{pr} \omega_{k}^{2} f\left(\xi_{n}\right)-2 p g\left(\xi_{n}\right) \omega_{k}+2} .
\end{aligned}
$$


Deasy Wahyuni, Mahdhivan Syafwan

\section{Penerapan Metode Persamaan Riccati Proyektif pada Persamaan Lotka-Voltera Diskrit}

Persamaan Lotka-Voltera diskrit diberikan oleh [4]

$$
u_{n}^{\prime}=u_{n}\left(u_{n+1}-u_{n-1}\right) \text {. }
$$

Persamaan ini merupakan generalisasi dari persamaan Lotka-Voltera atau persamaan mangsa-pemangsa (predator-prey) untuk dua spesies [5].

$$
\begin{aligned}
& \frac{d x}{d t}=\alpha x-\beta x y, \\
& \frac{d y}{d t}=\delta x y-\gamma y,
\end{aligned}
$$

dimana

$x$ : banyaknya mangsa,

$y$ : banyaknya pemangsa,

$\frac{d x}{d t}, \frac{d y}{d t}$ : laju pertumbuhan populasi mangsa dan pemangsa terhadap waktu,

$t$ : waktu,

$\alpha, \beta, \delta, \gamma:$ parameter riil positif yang mendeskripsikan interaksi antar dua spesies.

Pada persamaan (3.1), fenomena mangsa-pemangsa terjadi pada tak-hingga spesies, dimana spesies ke- $n$ memangsa spesies ke- $(n+1)$ dan dimangsa oleh spesies ke- $(n-1)$. Dengan melakukan transformasi gelombang berjalan

$$
u_{n}(t)=U\left(\xi_{n}\right),
$$

dimana $\xi_{n}=d n+c t+\xi_{0}$, persamaan (3.1) menjadi

$$
c U^{\prime}\left(\xi_{n}\right)=U\left(\xi_{n}\right)\left[U\left(\xi_{n+1}\right)-U\left(\xi_{n-1}\right)\right] .
$$

Selanjutnya dengan mensubstitusikan persamaan (2.5) ke persamaan (3.2) dan kemudian melakukan prinsip dominant balance, diperoleh $N=1$, sehingga solusi persamaan (3.2) dapat ditulis sebagai

$$
U\left(\xi_{n}\right)=A_{0}+A_{1} f\left(\xi_{n}\right)+B_{1} g\left(\xi_{n}\right),
$$

dimana $f\left(\xi_{n}\right)$ dan $g\left(\xi_{n}\right)$ memenuhi persamaan Riccati proyektif (2.6) dan (2.7).

Selanjutnya akan ditinjau perkasus menurut analisis metode persamaan Riccati proyektif yang telah dibahas pada bagian sebelumnya.

Kasus (i): $p q<0$.

Berdasarkan penjelasan pada bagian sebelumnya, pada kasus ini terdapat hubungan antara $f\left(\xi_{n}\right)$ dan $g\left(\xi_{n}\right)$ yang diberikan oleh

$$
g^{2}\left(\xi_{n}\right)=1-2 r f\left(\xi_{n}\right)+\left(r^{2}+h^{2}-s^{2}\right) f^{2}\left(\xi_{n}\right) .
$$

Selanjutnya dari persamaan (2.25) dan (2.26) diperoleh

$$
\begin{aligned}
f\left(\xi_{n \pm 1}\right) & =\frac{-f\left(\xi_{n}\right)}{-\sinh \left(\omega_{ \pm 1}\right) g\left(\xi_{n}\right)-r f\left(\xi_{n}\right)+\cosh \left(\omega_{ \pm 1}\right) f\left(\xi_{n}\right) r-\cosh \left(\omega_{ \pm 1}\right)}, \\
g\left(\xi_{n \pm 1}\right) & =\frac{-\sinh \left(\omega_{ \pm 1}\right)-\cosh \left(\omega_{ \pm 1}\right) g\left(\xi_{n}\right)+\sinh \left(\omega_{ \pm 1}\right) f\left(\xi_{n}\right) r}{-f\left(\xi_{n}\right) r-\sinh \left(\omega_{ \pm 1}\right) g\left(\xi_{n}\right)+r f\left(\xi_{n}\right) \cosh \left(\omega_{ \pm 1}\right)-\cosh \left(\omega_{ \pm 1}\right)} .
\end{aligned}
$$


Karena $\omega_{k}=\xi_{n+k}-\xi_{n}$ dan $\xi_{n}=d n+c t+\xi_{0}$, maka $\omega_{ \pm 1}$ dapat ditulis sebagai

$$
\begin{aligned}
\omega_{1} & =\xi_{n+1}-\xi_{n}=d(n+1)+c t+\xi_{0}-\left(d n+c t+\xi_{0}\right)=d, \\
\omega_{-1} & =\xi_{n-1}-\xi_{n}=d(n-1)+c t+\xi_{0}-\left(d n+c t+\xi_{0}\right)=-d .
\end{aligned}
$$

Dengan mengganti $\omega_{ \pm 1}= \pm d$, substitusikan persamaan Riccati proyekif (2.6)-(2.7), persamaan (3.4), (3.5) dan (3.6) ke dalam persamaan (3.3). Selanjutnya tetapkan nol untuk semua koefisien dari $f^{i}\left(\xi_{n}\right) g^{j}\left(\xi_{n}\right)$, dengan $j=0,1$ dan $i=0,1, \cdots$, sehingga diperoleh suatu sistem persamaan nonlinier terhadap parameter-parameter $A_{0}, A_{1}, B_{1}, c$ dan $d$. Dengan menggunakan bantuan software MAPLE, diperoleh solusi

$$
\begin{aligned}
A_{1} & =-2 A_{0} r+2 A_{0} r \cosh (d), \quad B_{1}=0, \\
c & =2 A_{0} \sinh (d), \quad h= \pm \sqrt{s^{2}-\frac{2 r^{2}}{1+\cosh (d)}},
\end{aligned}
$$

dimana $A_{0}, d, s$, dan $r$ adalah konstanta sebarang, asalkan

$$
s^{2}>\frac{2 r^{2}}{1+\cosh (d)} \text {. }
$$

Perhatikan bahwa penetapan $d>0$ di awal menjamin nilai pecahan pada parameter $h$ tetap terdefinisi.

Selanjutnya substitusikan parameter-parameter pada persamaan (3.7) ke persamaan (2.18) dan (2.19), sehingga didapatkan solusi

$$
u_{n}(t) \equiv U\left(\xi_{n}\right)=A_{0}+\frac{-2 A_{0} r+2 A_{0} r \cosh (d)}{r+s \cosh \left(\xi_{n}\right) \pm \sqrt{s^{2}-\frac{2 r^{2}}{1+\cosh (d)} \sinh \left(\xi_{n}\right)}},
$$

dimana $\xi_{n}=d n+2 A_{0} \sinh (d) t+\xi_{0}$, dengan $A_{0}, d, r, s$ dan $\xi_{0}$ adalah konstantakonstanta yang dapat dipilih sebarang namun memenuhi syarat (3.8).

Khusus untuk nilai-nilai konstanta

$$
A_{0}=d=r=s=1, \quad \xi_{0}=0,
$$

dan dengan mengambil tanda + , profil solusi (3.9) pada saat $t=0$ dan $t=10$ ditunjukkan oleh Gambar 1. Dari gambar tersebut dapat dilihat bahwa solusi yang diperoleh merupakan soliton yang berjalan ke arah kiri dengan kecepatan konstan $c=2 A_{0} \sinh (d) \approx 2,35$.

Kasus (ii): $p q>0$.

Berdasarkan penjelasan pada bagian sebelumnya, hubungan antara $f\left(\xi_{n}\right)$ dan $g\left(\xi_{n}\right)$ pada kasus ini diberikan oleh

$$
g^{2}\left(\xi_{n}\right)=-1+2 r f\left(\xi_{n}\right)-\left(r^{2}-h^{2}-s^{2}\right) f^{2}\left(\xi_{n}\right) .
$$

Selanjutnya $f\left(\xi_{n \pm 1}\right)$ dan $g\left(\xi_{n \pm 1}\right)$ dapat diperoleh dari persamaan (2.32) dan (2.33), yaitu

$$
\begin{aligned}
& f\left(\xi_{n \pm 1}\right)=-\frac{f\left(\xi_{n}\right)}{-r f\left(\xi_{n}\right)-\cos ( \pm d)+\cos ( \pm d) f\left(\xi_{n}\right) r+\sin ( \pm d) g\left(\xi_{n}\right)} \\
& g\left(\xi_{n \pm 1}\right)=\frac{-\cos ( \pm d) g\left(\xi_{n}\right)+\sin ( \pm d) f\left(\xi_{n}\right) r-\sin ( \pm d)}{-r f\left(\xi_{n}\right)-\cos ( \pm d)+\cos ( \pm d) f\left(\xi_{n}\right) r+\sin ( \pm d) g\left(\xi_{n}\right)}
\end{aligned}
$$




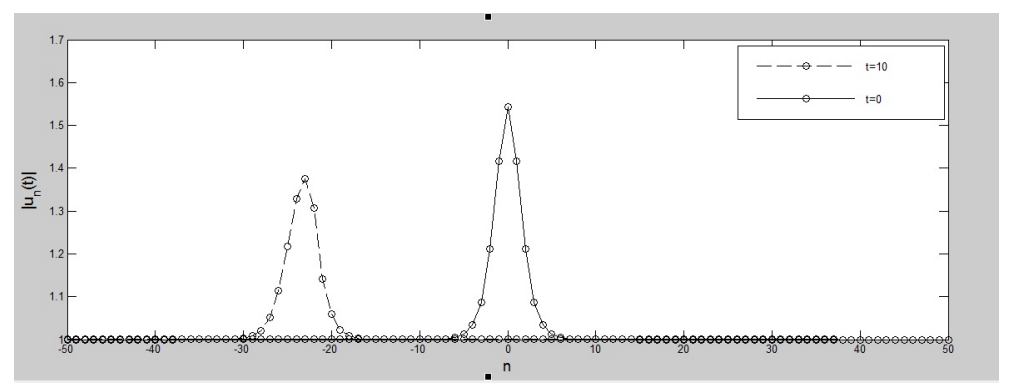

Gambar 1. Profil Solusi Persamaan Lotka Voltera Diskrit untuk Kasus (i)

dengan mengganti $\omega_{ \pm 1}= \pm d$. Dengan cara yang sama pada kasus (i), diperoleh solusi untuk parameter-parameter sebagai berikut:

$$
\begin{aligned}
A_{1} & =v-\frac{4 A_{0} r\left(-r^{2}+s^{2}+h^{2}\right)}{h^{2}+s^{2}}, \quad B_{1}=0, \\
c & =\frac{ \pm 4 r A_{0} \sqrt{-r^{2}+s^{2}+h^{2}}}{h^{2}+s^{2}}, \\
d & =\arctan \left(\frac{ \pm 2 r \sqrt{h^{2}+s^{2}-r^{2}}}{s^{2}+h^{2}}, \frac{2 r^{2}-h^{2}-s^{2}}{s^{2}+h^{2}}\right),
\end{aligned}
$$

dengan $A_{0}, r, s$, dan $h$ adalah konstanta sebarang asalkan $s \neq 0, h \neq 0$ dan $s^{2}+h^{2}>r^{2}$. Substitusikan parameter-parameter tersebut ke persamaan (2.28) dan (2.29), diperoleh solusi

$$
u_{n}(t) \equiv U\left(\xi_{n}\right)=A_{0}+\frac{-4 r A_{0}\left(s^{2}+h^{2}-r^{2}\right)}{\left(s^{2}+h^{2}\right)\left(r+s \cos \left(\xi_{n}\right)+h \sin \left(\xi_{n}\right)\right)},
$$

dimana

$$
\xi_{n}=\arctan \left(\frac{ \pm 2 r \sqrt{h^{2}+s^{2}-r^{2}}}{s^{2}+h^{2}}, \frac{2 r^{2}-h^{2}}{s^{2}+h^{2}}\right) n+\frac{4 r A_{0} \sqrt{s^{2}+h^{2}-r^{2}}}{s^{2}+h^{2}} t+\xi_{0} .
$$

Profil solusi (3.11) pada saat $t=1$ dan $t=5$ untuk nilai-nilai konstanta

$$
A_{0}=d=r=s=1, \quad \xi_{0}=0,
$$

dan dengan mengambil tanda + , ditunjukkan pada Gambar 3.1.2. Dari gambar tersebut dapat dilihat bahwa solusi berjalan ke arah kanan sambil berosilasi secara bergantian di setiap site- $n$.

Kasus (iii): $q=0$.

Berdasarkan penjelasan pada bab sebelumnya, hubungan antara $f\left(\xi_{n}\right)$ dan $g\left(\xi_{n}\right)$ pada kasus ini diberikan oleh

$$
g^{2}\left(\xi_{n}\right)=\frac{2 r f\left(\xi_{n}\right)}{p}+\frac{\left(C_{1}^{2}+4 C_{2} p r\right) f^{2}\left(\xi_{n}\right)}{4 p^{2}} .
$$




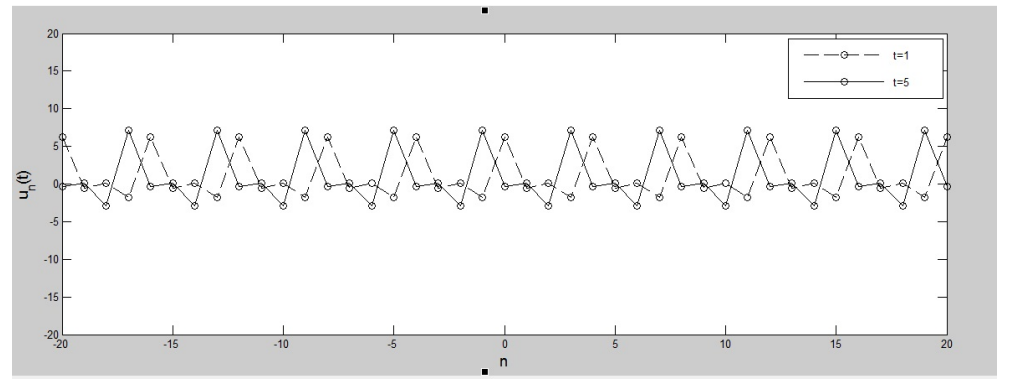

Gambar 2. Profil Solusi Persamaan Lotka-Voltera Diskrit untuk Kasus (ii)

Selanjutnya dari persamaan (2.40) dan (2.41) dan dengan mengganti $\omega_{ \pm 1}= \pm d$, diperoleh

$$
\begin{aligned}
& f\left(\xi_{n \pm 1}\right)=\frac{2 f\left(\xi_{n}\right)}{\operatorname{prd}^{2} f\left(\xi_{n}\right)-2 p g\left(\xi_{n}\right)( \pm d)+2}, \\
& g\left(\xi_{n \pm 1}\right)=\frac{2 g\left(\xi_{n}\right)-2 f\left(\xi_{n}\right) r( \pm d)}{\operatorname{prd}^{2} f\left(\xi_{n}\right)-2 p g\left(\xi_{n}\right)( \pm d)+2} .
\end{aligned}
$$

Dengan cara yang sama pada kasus (i), diperoleh solusi untuk parameter-parameter sebagai berikut:

$$
A_{1}=-2 d^{2} r A_{0} p, \quad B_{1}=0, \quad c=2 d A_{0}, \quad C_{2}=-\frac{C_{1}^{2}-p^{2} r^{2} d^{2}}{4 r p},
$$

dengan $A_{0}, r, p, d, C_{1}$ dapat dipilih sebarang asalkan $r \neq 0$ dan $p \neq 0$.

Substitusikan parameter-parameter tersebut ke persamaan (2.35) dan (2.36), sehingga didapatkan solusi

$$
u_{n}(t) \equiv U\left(\xi_{n}\right)=A_{0}-\frac{2 A_{0} d^{2} p r}{p r \xi_{n}^{2}+C_{1} \xi_{n}-\frac{p^{2} r^{2} d^{2}-C_{1}^{2}}{4 r p}},
$$

dengan $\xi_{n}=d n+2 A_{0} d t+\xi_{0}$.

Profil solusi (3.16) pada saat $t=1.1$ dan $t=5.1$ untuk nilai-nilai konstanta $A_{0}=r=p=d=C_{1}=1$ dan $\xi_{0}=0$ ditunjukkan pada Gambar 3. Dari gambar tersebut dapat dilihat bahwa solusi yang diperoleh merupakan soliton yang berjalan ke arah kiri dengan kecepatan konstan $c=2 A_{0} d=2$.

\section{Ucapan Terima kasih}

Penulis mengucapkan terima kasih kepada Bapak Dr. Admi Nazra, Bapak Prof. Dr. Syafrizal Sy, Bapak Dr. Jenizon, dan Ibu Dr. Lyra Yulianti yang telah memberikan masukan dan saran sehingga paper ini dapat diselesaikan dengan baik.

\section{Daftar Pustaka}

[1] Conte, R., dan Musette, M., (1992), Link Between Solitary Waves and Projective Riccati Equations, J. Phys. A 25, 5609. 


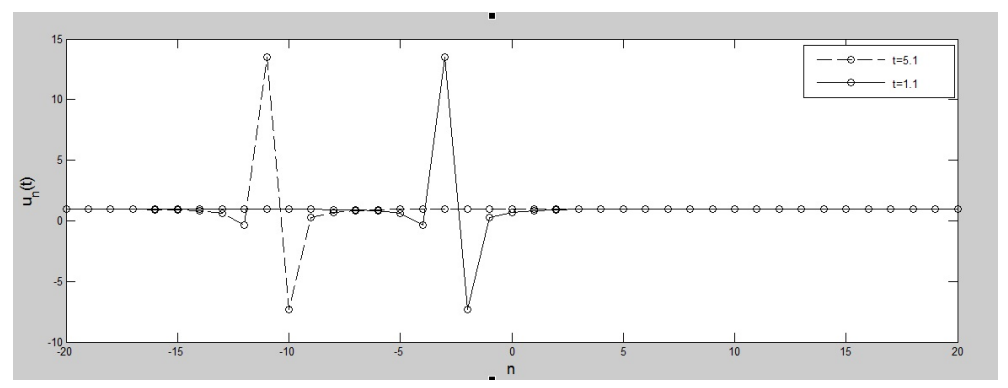

Gambar 3. Profil Solusi Persamaan Lotka-Voltera Diskrit untuk Kasus (iii)

[2] Drazin, P. G., dan Johnson, R. S., (1989): Solitons: An Introduction, Cambridge University Press, Cambridge.

[3] Gorguis, A., dan Chan, W. K. B., (2008): Heat equation and its comparative solutions, Computers and Mathematics with Applications 55 (12) : 2973 - 2980.

[4] Itoh, Y., (1987), Integrals of a Lotka-Voltera System of Odd Number of Variables, Prog. Theor. Phys. 78(3), 507.

[5] LotkaVolterra equations. https://en.wikipedia.org/wiki/Lotka \%E2\%80\%93Volterra_equations, diakses pada 2 Januari 2016.

[6] Wazwaz, A. M., (2009): Partial Equations and Solitary Waves Theory, Springer, Berlin Heidelberg.

[7] Yan, Z., (2003), Generalized method and its application in the higher-order nonlinear Schrödinger equation in nonlinear optical fibres, Chaos, Solitons and Fractals 16, 759 .

[8] Zhen, W., dan Hong-Qing, Z., (2006). New Exact Solutions to Some Difference Differential Equations, Chinese Physics 15(10) : 2210 - 2215. 